\title{
A Panel Priority Rating Exercise for the British Forces Germany Health Services Market Test
}

\author{
Lt Col TO Jefferson \\ MSc, MRCGP, MFPHM, DRCOG, DTM\&H, RAMC \\ Consultant in Public Health Medicine
}

G1 Market Testing, HQ UKSC(G), BFPO 140

\author{
Prof V Demicheli \\ MD, MSc \\ Professor of Medical Statistics
}

University of Pavia, 27100 Pavia, Italy

SUMMARY: We report on the application to the BFG Health Services Market Testing (MT) study of the response to a users' questionnaire and panel discussions to determine in which priority and how services should be provided. The questionnaire served to inform lay and health care panel members on users' views on the relative importance of future health services and the way they will be provided. Based on the questionnaire results and data contained in the BAOR Report of Public Health for 1992/93 the panel assigned the highest priorities to emergency services, followed by routine General Practitioner services and essential hospital services. The lowest ranking were non-essential hospital services, health care for children with special needs and provision of designated transport. There was a high consistency in views between the lay and health care members of the panel

\section{Introduction}

The aim of the British Forces Germany (BFG) Health Services Market Test (MT) is to improve services through the introduction of managed competition. The core of any MT exercise is the definition of the Statement of Requirement (SOR) which sets out the services and correspondent standards which potential providers must bid to provide. The proper definition of the SOR is therefore the key to any successful MT as it will form the basis of the future contractual relationship between the "purchaser" (in this case the representatives of the General Staff) and any future provider (either private companies, or NHS Trusts, or the Army Medical Services or a combination thereof). At the same time the health requirements of a population are subject to change, and the highly mobile, young and fertile population of BFG is no exception. The methods used to identify the service needs of the BFG population must therefore be universal and frequently updatable.

As health care resources dwindle and health care costs increase it has become vital to establish which health services are to be regarded as core and which as less important.

This requirement has led to several experiments in industrialised countries to ascertain a ranking list of priorities for health services (1). Some of these have involved users' views in the determination of the relative importance of services in order to ensure a more equitable distribution of resources and for trade-offs between actual capabilities and aspirations to be made explicit (2).

Perhaps the most famous and controversial priority setting experiment has been that carried out in the

American State of Oregon (3). The Oregon experimer achieved a list of 17 prioritised groups (or categories care) through massive involvement of the public ane attainment of consensus on the process.

The method employed in the Oregon experiment is on one of many possible methodologies used. An up to date review is available (4). All rationing, either explicit of implicit, involves however a delicate trade-off between efficiency, effectiveness and equity of interventions. No magic formula exists which allows perfect preservation of all three. Public involvement may therefore be important to make these trade-offs explicit and acceptable.

We report on the application to the BFG Health Services MT study of the response from a users' questionnaire and panel discussions to determine in which priority and how services should be provided.

The BAOR community is relatively tightly knit and with a limited range of health problems because of selfselection, high physical fitness and relative youth of the population. The strong community spirit led us to recognize the importance of canvassing the widest possible range of users as well as commanders. We tried to reach a consensus on the difficult issue of how many resources to allocate to which services.

We never considered or discussed operationally vital $\rightarrow$ services such as the back-up to the Field Army in wartime. Such assets are outside the scope of the MT $N$ study.

The aim of this report is to describe the methods used to achieve agreement on the priorities to be assigned to health services and present the results. 


\section{Methods}

In the first phase we consulted the public and out of the wide range of methods available (5) we chose a simple anonymous two-page questionnaire which required respondents to rank separately interventions and characteristics of services in order of importance, together with a few personal details.

The questionnaire was distributed widely throughout the Command using the Station Staff Officer's (SSO) net and publicised through a media campaign. We considered random sampling techniques but reluctantly rejected this approach because of cost. We tried to distribute the questionnaire as widely as possible with the objective of distributing one questionnaire per household. Coverage was enhanced by local reproduction by several garrison magazines.

The services and characteristics in the questionnaire had been chosen from discussions in focus groups on specific topics (where we acted as facilitators). The questionnaire used is reproduced at Appendix A.

We summarised the information contained in 488 correctly returned questionnaires (approximately $3.2 \%$ of households) and decided to exclude 65 incorrectly compiled questionnaires. We further carried out an analysis comparing the profile of personal details of those who responded correctly and those whose questionnaires were excluded. Difference of means and proportions were tested respectively using Student's t and chi-square tests.

We carried out simple linear extrapolation manipulations on 160 questionnaires in which some mistakes had been made. The commonest were repeated rankings and limited range of ranks. Such manipulations allowed us to salvage the questionnaires and the data contained.

We compared ranks of interventions and characteristics from the two batches of questionnaires using nonparametric tests such as Wilcoxon's two-sample test.

We summed up ranks of importance given by users to services and their characteristics using median, 25th and 75 th percentile of ranks because of skewness (asymmetry) of rank distribution.

In order to relate users' views with the views of health care workers we organised a priority setting panel discussion. This consisted of a structured meeting of a lay panel and a health care panel. Both panels were even numbered and their composition is shown at Annex A.

\section{Lay Panel Composition}

Deputy Assistant Chief of Staff (G1) representing the Army

Federation of Army Wives representative

Single soldier representative

Ministry of Defence Civil Service representative

Health Care Workers' panel

Public Health representative

General Practice representative
Hospital Practice representative

Community nurse

Royal Air Force Medical Services representative (observer).

Both panels were "primed" by being asked to read the BAOR Report of Public Health 1992-93 (6) (lay panel) and the preliminary findings of the Priority Rating Questionnaires (the health care workers panel).

Consensus was achieved by two rounds of individual, panel and plenary discussions interspersed with increasing anonymous feed-back. Each round was made first of a self-generated list of services and then a priority voting.

These methods are known as Nominal Group Techniques (7) and Delphi (8) Technique which had been adapted by us to fit a military setting.

\section{Results}

Table 1 shows the personal characteristics of all respondents. The profile is consistent with household of respondents being those of senior ranks and officers, $71 \%$ with children (with 1.9 children each), living in a garrison, a short distance away from the medical centre. 93.2\% had had a contact with a medical facility in the previous six months, a very high but not unexpected utilization rate.

The profiles of respondents whose questionnaires were excluded or included in the study are not significantly different.

Rankings of services and characteristics are shown it Tables 2 and 3.

Table 1.

Personal characteristics of all questionnaire respondents. For explanation see text

\begin{tabular}{cc}
\hline Characteristics & Profile \\
\hline Mean age & 34.6 \\
\% with children & 71 \\
\% previous contact with health services & 93.2 \\
\% medical centre & 85.0 \\
\% BMH contact & 43.0 \\
\% Krankenhaus contact & 8.0 \\
\% living in barracks & 6.2 \\
\% living in garrison & 54.2 \\
\% living in patch & 39.5 \\
travel time (minutes) & 12.6 \\
\hline
\end{tabular}

Table 2.

Top nine ranking services according to questionnaire respondents. For explanation see text

\begin{tabular}{cc}
\hline SERVICES & RANK \\
\hline Ante and Post Natal & 1 \\
School Health Service & 2 \\
Minor Surgery at your medical centre & 2 \\
Health Visiting and Community Support & 2 \\
Family Planning & 3 \\
Physiotherapy & 3 \\
Health Education Activities & 4 \\
Infertility Treatment & 5 \\
\hline
\end{tabular}


APPENDIX A

PLEASE ONLY FILL IN AND RETURN ONE QUESTIONNAIRE PER HOUSEHOLD

What ranking would you give to the following services? (rank 1 to 10)

1. Ante and post natal (pregnancy and afterwards)

2. School health service (School doctor/nurse)

3. Infertility treatment

4. Minor surgery at your medical centre (including foot care)

5 . Health visiting and community support

6. Health education activities (e.g. campaigns against alcohol, tobacco, accidents etc.)

7. Family Planning (contraception and advice on contraception)

8. Physiotherapy

9. Other (specify)

10. Other (specify)

What ranking would you give to the following characteristics of the health service? (rank 1 to 6 )

11. English spoken as a first language by staff

12. Comfort

(a clean, friendly environment with TV, Radio, magazines and good meals)

13. Ease of access

(a relatively short travelling time from home and long opening hours)

14. British style practice (the way things are done at home)

15. English spoken as a second language by staff

16. Other (specify)

17. Have you been in contact with health services in the last six months? Yes/No

If you have answered Yes, where did that contact take place?
a. Medical Centre
c. German Hospital
b. BMH
d. Other
(specify)

18. How old are you? ..... years

19. Have you got any children living with you? Yes/No

20. If you have answered yes, please list their ages (including any children you may have at boarding school):

Living at home

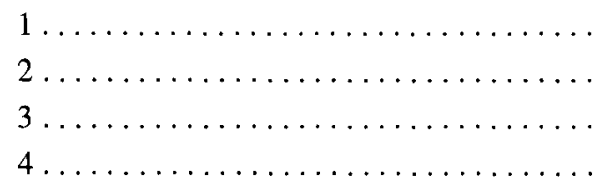

At boarding school

$$
1 \text {. }
$$

3

4

21. Where is your quarter?
a. In a barracks
b. Within a garrison
c. In a patch not within a garrison

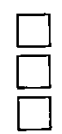

22. What is the average travelling time from your quarter to the nearest medical facility?
a.
hours
b. .minutes 
Table 3.

Preferred characteristics of services according to questionnaire respondents. Ease of access $\left(^{*}\right)$ was further mentioned by 79 respondents in other parts of the questionnaire without ranking. For explanation see text.

\begin{tabular}{cc} 
CHARACTERISTICS & RANK \\
\hline English spoken as first language by staff & 1 \\
Ease of access & $2^{*}$ \\
Comfort & 2 \\
British style practice & 4 \\
English spoken as a second language & 5
\end{tabular}

Figures 1 and 2 show the relative spatial distribution of preference scores $(25$ th percentile, median and 75 th percentile). Some difference in median rankings between responses in readily usable and manipulated questionnaires had no influence on the aggregate final ranking.

Ante and

Post Natal

Service

School health

Service
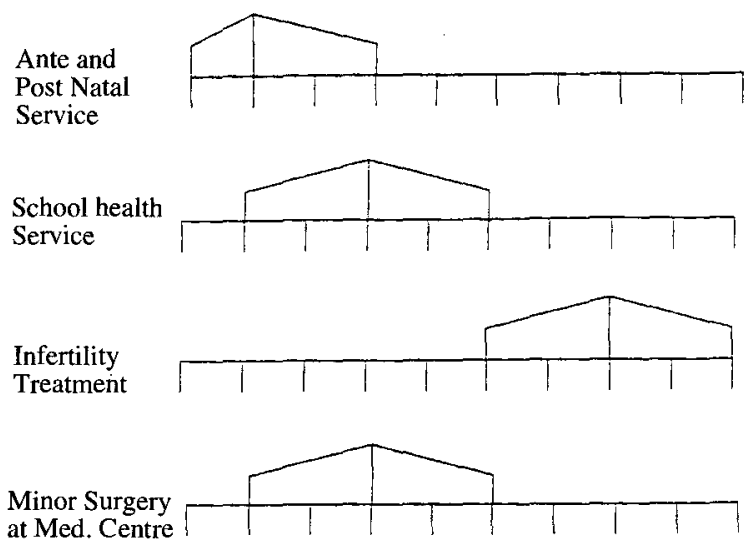

at Med Centre

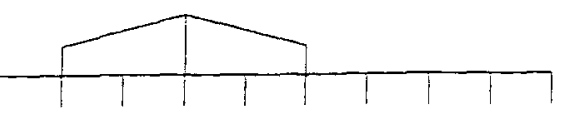

Community

Support

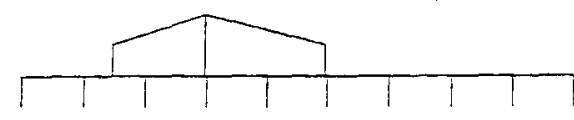

Health

Education

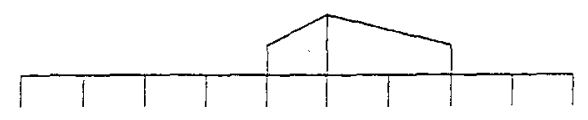

Family

Planning
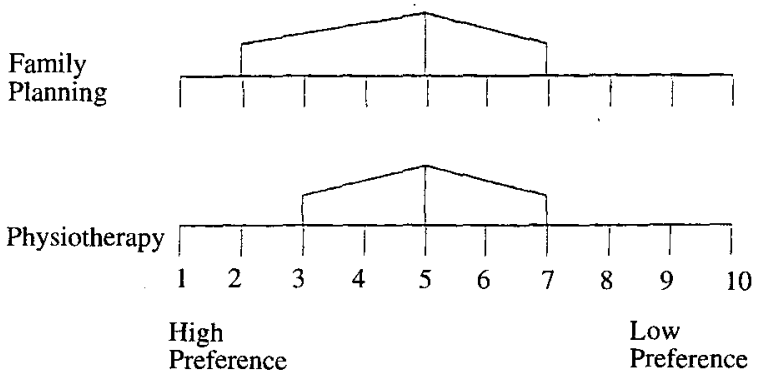

Fig 1. Spatial distribution of preference scores for services (25th percentile, median, 75th percentile)
In the open answers to the sections of the questionnaire requesting views, well-woman clinics were requested by 59 respondents, dental prevention by 22 respondents and "counselling" by 17 respondents.

The need for ease of access was reinforced by 79 respondents.

Some typical comments we received with the questionnaires were:

"I don't like having to give my husband's last three digits of his Service number" and "I would be very sorry to see British Medical Services reduced to benefit the Treasury".

Mean priority rating scores divided by panel and as an aggregate in the final assessment are shown in Table 4 and as ranks in Table 5. The symbols ${ }^{\wedge}$ and ${ }^{*}$ denote a statistically significant difference in score for each panel, that is not likely to be due to chance. Throughout low scores denote the highest priorities. Not surprisingly, the highest ranking services were life-saving emergency provisions and routine GP and hospital services (for example orthopaedic surgery).

English as 1st language

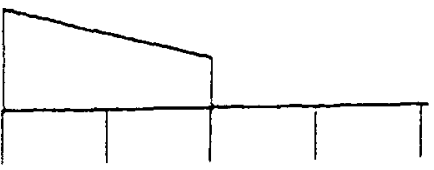

Comfort

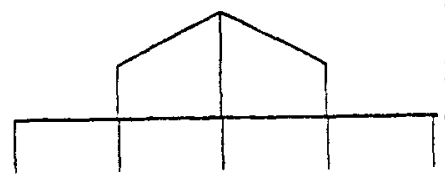

Access

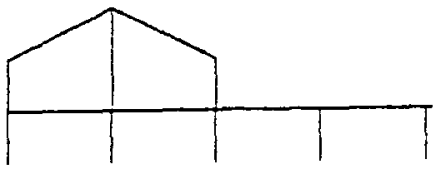

British

Style

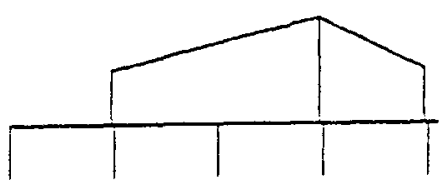

English as 2nd language
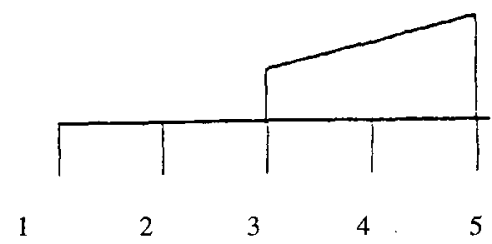
2 3

4

5

High Low Preference

Preference

Fig 2. Spatial distribution of preference scores for characteristics of services (25th percentile, median, 75th percentile) 
The lowest ranking services were non-essential hospital ones (such as cosmetic plastic surgery and high technology procedures) health care for children with special needs and provision of designated transport.

Table 4.

Mean priority rating scores by panel in the final assessment. $\wedge$ and $*$ Denote a statistically significant difference ( $p<0.034$ for $^{\wedge}$ and 0.027 for ${ }^{*}$ ) in the score for each panel. Low scores denote the highest priorities. For explanation see text.

\begin{tabular}{|c|c|c|c|}
\hline Services & Lay & $\begin{array}{c}\text { Health } \\
\text { Care } \\
\text { Workers }\end{array}$ & All \\
\hline Preventive - well woman & 11.5 & 11.7 & 11.6 \\
\hline Preventive - immunisations & 5.5 & 5.5 & 5.5 \\
\hline Preventive - dental & 8.2 & 13 & 10.6 \\
\hline Preventive - Health Education & 10.5 & 12.2 & 11.3 \\
\hline Health visiting & 7.7 & 11.2 & 9.5 \\
\hline Community psychiatric support & 10.7 & 10 & 10.8 \\
\hline Other community support - lay & 18.2 & 16.2 & 17.2 \\
\hline Children with special needs & 17 & 19.5 & 18.2 \\
\hline Community paediatrics & 10.7 & 6 & $8.3^{\wedge}$ \\
\hline Community obstetrics & 13 & 4 & $8.5^{*}$ \\
\hline Routine GP services & 2.2 & 2 & 2.1 \\
\hline 24 hour A \& E service & 1 & 1 & 1 \\
\hline Chronic disease clinics & 13.2 & 17 & 15.1 \\
\hline Primary Dental Care & 11.2 & 9.2 & 10.2 \\
\hline Rehabilitation & 12.2 & 9.5 & 10.8 \\
\hline Minor operations & 8.2 & 13.5 & 10.8 \\
\hline Dispensing & 13.2 & 14 & 13.6 \\
\hline Transport & 19.5 & 15.2 & 17.3 \\
\hline Family planning & 12.5 & 8.5 & 10.5 \\
\hline Essential hospital services & 2.7 & 3 & 2.8 \\
\hline Desirable hospital services & 20.5 & 20.5 & 20.5 \\
\hline
\end{tabular}

Table 5. Rank of services according to both panels in the final assessment. 1 denotes the highest priority and 21 denotes the lowest. For explanation see text.

\section{SERVICES}

RANK

Preventive - well woman clinics

Preventive - immunisations

Preventive - dental

Preventive - Health Education

Health visiting

Community psychiatric support

Other community support - Iay

Children with special needs

Community paediatrics

Community obstetrics

Routine GP services

24 hour A \& E service

Chronic disease clinics

Primary Dental Care

Rehabilitation

Minor operations

Dispensing

Transport

Family planning

Essential hospital services

Desirable hospital services

\section{Discussion}

We estimate that around only $3 \%$ of households responded.

We are unable to assess how many questionnaires were distributed as we lacked resources for face-to-face administration. However, response rate is usually low in any such venture, especially for postal questionnaires and the purpose of the questionnaire was to inform panel discussants. Usually respondents are a self-selected subset of people with clearly defined ideas. The relatively high mean age of our respondents leads us to suspect that the majority of respondents are mature individuals probably of Officer and Warrant Officer status, a high proportion of which have children.

The general firmness of opinions in our sample is confirmed by the relatively tight spatial distribution of preference scores for services and the way they should be delivered as shown in Figures 1 and 2. The only services excepted are Family Planning and Minor Surgery.

Such a communality of perceptions and goals is also evident in the results of the panel discussions where Community Paediatrics and Community Obstetrics are the only services the rankings of which differ significantly between panels.

For the same reasons the consensus-making process went relatively smoothly with few fluctuations in the rankings and with 8 services maintaining their ranking throughout the process.

The consensus was highest in the high and low priority ends of the spectrum. This is consistent with the outcome of similar exercises where the first concern was to maintain life-saving services.

At a first glance the apparent demotion of designated transport to rank nineteenth is difficult to explain (Table 5). However this item of service was only introduced by a panel discussant. Questionnaire respondents rate it as second in importance as a Service Characteristic under ease of access (Table 3), a view which appears more in keeping with general perceptions. Ease of access is of course a far more comprehensive term than simple provision of designated transport.

Attempts at explicit rationing of health care services on the basis of the effectiveness and efficiency of interventions are being made in the National Health Service. These are however at an initial stage due to the infancy of the methodologies used to sum-up evidence. We are developing a method to sum-up all the evidence needed to define the health services requirement of our population. This method, called Epidemiological Needs Assessment in a Military Environment (ENAME), will combine epidemiological, effectiveness and economic data to guide purchasing choices and monitor outcomes. It will take the priorities identified by this exercise into account when determining services.

The views expressed both by panellists and questionnaire respondents are probably representative only of the 500-odd persons who took part. On the one 
hand such views must be taken into account but enhancement of future response is highly desirable. Such an enhancement could take place both if Garrison panels were set up and elements of the next priority rating exercise were to be included (probably at a low marginal cost) in routine exercises such as the Continuous Attitude Survey. We recommend the use of the method described to ascertain health care priorities in other military community environments.

\section{REFERENCES}

1. Bowling A. What people say about prioritising health services. King's Fund Centre. London 1993.

2. Anonymous. Future health care options: distribution of health care resources, decisions and choices. Institute of Health Service Management. London 1993.
3. Klevit HD, Bates AC, Castanares T, et al. Prioritization of health care services. A progress report by the Oregon Health Services Commission. Arch Intern Med 1991; 151: 912-16.

4. Anonymous. Health Priority Setting. King's Fund. College. London 1993.

5. Department of Health, NHS Management Executive. Local voices. The views of local people in purchasing for health. London DOH 1992.

6. Medical Directorate Headquarters British Army of the Rhine. Report of Public Health 1992/93. (Unpublished).

7. Delberq AL, VAN de Ven AH. A group process. model for problem identification and programmeplanning. J Appl Behav Sci 1971; 7: 466-92.

8. Dalkey NC, Helmer O. An experimental application of the Delphi method to the use of experts. Management Sciences 1963; 9: 458-67. 